\title{
Resistance Exercise Did Not Alter Intramuscular Adipose Tissue but Reduced Retinol-binding Protein-4 Concentration in Individuals with Type 2 Diabetes Mellitus
}

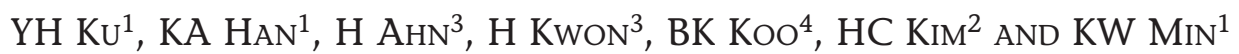

${ }^{1}$ Department of Internal Medicine, and ${ }^{2}$ Department of Radiology, Eulji University School of Medicine, Daejeon, Republic of Korea; ${ }^{3}$ Diabetes Centre, Eulji Hospital, Seoul, Republic of Korea; ${ }^{4}$ Department of Internal Medicine, Seoul National University College of Medicine, Seoul, Republic of Korea
\end{abstract}

Lipid accumulation in muscle is associated with diminished insulin sensitivity. It was hypothesized that resistance exercise decreases muscular adipose tissue and reduces the level of retinol-binding protein-4 (RBP4), which is linked to adipose tissue and insulin sensitivity in diabetics. Forty-four women with type 2 diabetes were randomly assigned to three groups for a period of $\mathbf{1 2}$ weeks: control (asked to maintain a sedentary lifestyle); resistance exercise (elastic band exercise at moderate intensity five times per week); and aerobic exercise (walking for $60 \mathrm{~min}$ at moderate intensity five times per week).
Subcutaneous (SCAT), subfascial (SFAT) and intramuscular (IMAT) adipose tissues at mid-thigh level were assessed using computed tomography, and RBP4 level and insulin sensitivity (fractional disappearance rate of insulin, $k_{\mathrm{IIT}}$ ) were assessed before and after intervention. Changes in SCAT, SFAT, IMAT, RBP4 and $k_{\text {IIT }}$ were similar among the three groups. Within-group analysis revealed that body mass index and waist circumference decreased significantly in both exercise groups, but RBP4 decreased significantly only with resistance exercise. Resistance exercise did not alter muscular adipose tissue or improve insulin sensitivity.

\section{KEY WORDS: Diabetes MelLITUS tYPe 2; INSULIN RESISTANCE; ResistanCE tRAINING;}

\section{RetinOL-BINDING PROTEINS; Adipose tISSUE}

\section{Introduction}

Evidence has shown that an excess supply of fatty acids, beyond that required for energy needs, is a cause of insulin resistance in muscle. ${ }^{1,2}$ Intramyocellular triglyceride accumulation is a marker of an excessive supply of fatty acid to muscle and studies have demonstrated an association between intramyocellular triglyceride accumulation and insulin resistance..$^{3-5}$ In addition, 


\section{Resistance exercise in individuals with diabetes mellitus}

circulating adipokines, such as retinolbinding protein-4 (RBP4), leptin and adiponectin, are emerging as important links between obesity, insulin resistance and type 2 diabetes mellitus. ${ }^{6-9}$

A universally accepted component of the non-pharmacological treatment of type 2 diabetes mellitus is exercise. ${ }^{10}-12$ In particular, resistance training studies have revealed positive relationships between resistance exercise and glycaemic control. ${ }^{13,14}$ Although the precise mechanisms underlying the positive effects of resistance training remain to be clarified, one process may be through the downregulation of pro-inflammatory factors. Acute phase reactants, cytokines and adipokines have recently been implicated in the pathogenesis of type 2 diabetes mellitus. ${ }^{15}$ Limited research has been conducted to examine the effects of resistance training on these proinflammatory factors, which may present an opportunity for improved management of type 2 diabetes mellitus.

It is reasonable to hypothesize that resistance exercise decreases muscular adipose tissue, and that it may also have favourable effects on RBP4 which is linked to adipose tissue accumulation in muscle and insulin sensitivity in individuals with diabetes. In the present study, the effect of resistance and aerobic training on regional adipose tissues, levels of adipokines especially RBP4 - and insulin resistance was investigated in overweight Korean women with type 2 diabetes mellitus.

\section{Patients and methods PATIENTS}

Overweight Korean women (body mass index $[\mathrm{BMI}]>23 \mathrm{~kg} / \mathrm{m}^{2}$ ) with type 2 diabetes who were attending the Diabetes Centre at Eulji Hospital, Seoul, Republic of Korea, were enrolled sequentially into the study between August and October 2008. All patients had taken > $1 \mathrm{~g}$ /day metformin for $>3$ months previously and were on a stable antidiabetes regimen (sulphonylurea and metformin). Patients receiving lipid-lowering medications, insulin or thiazolidinediones were excluded. Individuals with diabetic vascular complications, life-threatening diseases, orthopaedic problems, or liver and renal impairment were also excluded. During the intervention period, all participants were asked to maintain a standard calorific intake (ideal body weight [in $\mathrm{kg}$ ] $\times 30 \mathrm{kcal} / \mathrm{kg}$ [kcal] per day), and they were monitored by self-report once every 2 weeks. The patients were randomly assigned to undertake resistance exercise, aerobic exercise or no exercise (control group).

The study protocol was reviewed and approved by The Institutional Review Board of Eulji Hospital, Seoul, Republic of Korea, and written informed consent to participate in the study was obtained from all patients.

\section{EXERCISE TRAINING}

Subjects in the resistance and aerobic exercise groups took part in a 12-week programme of exercise, according to the protocol, under individual supervision. Participants in the resistance exercise group performed elastic band exercise at about $40-50 \%$ of maximal exercise capacity five times per week - three times as part of a group in the hospital gymnasium and twice at home. Elastic band exercise comprised three sets of $15-20$ repetitions, with 10 different motions that included biceps curl, triceps extension, upright row, shoulder chest press, trunk sidebending, seated row, leg press, hip flexion, leg flexion and leg extension. The aerobic training group exercised by walking for 60 min at moderate intensity (3.6 - 5.2 metabolic equivalents [METs - a multiple of 


\section{Resistance exercise in individuals with diabetes mellitus}

resting oxygen consumption where 1 MET equals a person's oxygen uptake at rest, i.e. approximately $3.5 \mathrm{ml}$ oxygen/kg body weight per min]) five times per week. The control group had experience of diabetes education, including benefits of diet and exercise, but did not receive any additional education during this study; they were asked to maintain their sedentary lifestyle. All participants received information about how to monitor their diet and exercise. Daily activities of all the participants were monitored with a Lifecorder ${ }^{\circledR}$ (Suzuken Co., Nagoya, Japan) and dietary intake was selfreported, using a 3-day diet diary.

\section{LABORATORY AND CLINICAL MEASUREMENTS}

On the first and last testing days, each participant's height and weight were measured. Body composition, including fat mass, fat-free mass, muscle mass and regional fat content, were assessed using dual-energy X-ray absorptiometry (DXA; Lunar Prodigy ${ }^{\circledR}$, GE Healthcare Biosciences, Piscataway, NJ, USA) and all scans were analysed by one investigator (H.K.). The amount of regional adipose tissue subcutaneous (ASAT) and visceral adipose tissue (AVAT) in the abdomen, and subcutaneous (SCAT), subfascial (SFAT) and intramuscular adipose tissue (IMAT) at midthigh level - was measured using computed tomography. In addition, muscle strength was tested by measuring one repetitive maximum (1RM) for the upper and lower extremities using a chest and leg press, respectively $\left(\right.$ Keiser $^{\circledR}$, Fresno, CA, USA), before and after the 12-week exercise programme. Muscle power of the upper extremities was measured in the deltoid, triceps and pectoralis muscles and, for the lower extremities, it was measured in the gluteal group, hamstring and quadriceps muscles. To measure 1RM, all patients performed a 5-min warm-up of mild stretching. After resting for $1 \mathrm{~min}$, patients then performed three sets at $10 \%$ of maximal capacity, separated by $1-\mathrm{min}$ rest intervals. Finally, patients performed three sets of repetitions at $90 \%$ of estimated maximal intensity.

Venous blood samples were drawn after $12 \mathrm{~h}$ of fasting at weeks 0 and 12 . Samples were centrifuged and serum was removed and frozen at $-70^{\circ} \mathrm{C}$ for later analysis. Fasting plasma glucose level, glycosylated haemoglobin $\left(\mathrm{HbA}_{1 \mathrm{c}}\right)$, fasting C-peptide, lipid profiles, plasma levels of RBP4, leptin and adiponectin, and insulin sensitivity (insulin tolerance test: fractional disappearance rate of insulin $\left[k_{\mathrm{ITT}}\right]$ ) were measured before and after the 12-week exercise programme.

\section{STATISTICAL ANALYSIS}

It was calculated that a sample size of 45 persons (15 per group) was needed to have $80 \%$ power to detect a moderate ( $S D \pm 0.65$ ) difference for each of the four comparisons tested simultaneously, with an overall value of $P=0.05$. All data were analysed using the SPSS $^{\circledR}$ statistical package, version 12.0 (SPSS Inc., Chicago, IL, USA) for Windows ${ }^{\circledR}$. Variables that were not normally distributed were logarithmically transformed before statistical analysis. The results are presented as means \pm SD. Analysis of variance was used to evaluate the changes across groups, post hoc test (the least significant difference test) was used for pair-wise comparisons, and univariate analysis was used to assess the correlation of the changes in parameters. A $P$ value $<0.05$ was considered to be statistically significant.

\section{Results}

The study included 44 overweight women 
YH Ku, KA Han, H Ahn et al.

\section{Resistance exercise in individuals with diabetes mellitus}

with type 2 diabetes who were assigned randomly to the resistance exercise group ( $n$ $=13)$, the aerobic exercise group $(n=15)$ or the control group $(n=16)$. They ranged in age from 38 to 68 years and their baseline characteristics are shown in Table 1. No significant differences were observed in any variable between the three groups at baseline with the exception of $k_{\mathrm{ITT}}$, which was higher in the aerobic exercise group than in the resistance exercise or control groups ( $P=0.011$ across-group comparison).

Changes in all variables after 12 weeks compared with baseline are listed in Table 2. In the two exercise groups, anthropometric variables were significantly different from

\section{TABLE 1:}

Baseline characteristics of 44 women with type 2 diabetes mellitus before taking part in a 12-week programme of no exercise (control), resistance exercise or aerobic exercise

\begin{tabular}{|c|c|c|c|c|}
\hline \multirow[b]{2}{*}{ Characteristic } & \multicolumn{3}{|c|}{ Group } & \multirow[b]{2}{*}{$\begin{array}{c}\text { Statistical } \\
\text { significance }^{\mathrm{a}}\end{array}$} \\
\hline & $\begin{array}{l}\text { Control } \\
(n=16)\end{array}$ & $\begin{array}{c}\text { Resistance } \\
\text { exercise } \\
(n=13)\end{array}$ & $\begin{array}{l}\text { Aerobic } \\
\text { exercise } \\
(n=15)\end{array}$ & \\
\hline Age (years) & $57.8 \pm 8.1$ & $55.7 \pm 6.2$ & $55.7 \pm 7.0$ & NS \\
\hline Diabetes duration (years) & $5.8 \pm 6.1$ & $5.7 \pm 4.8$ & $6.6 \pm 5.3$ & NS \\
\hline Weight $(\mathrm{kg})$ & $67.6 \pm 7.5$ & $66.1 \pm 4.4$ & $66.3 \pm 6.0$ & NS \\
\hline Waist circumference $(\mathrm{cm})$ & $90 \pm 12$ & $90 \pm 5$ & $89 \pm 5$ & NS \\
\hline $\mathrm{BMI}\left(\mathrm{kg} / \mathrm{m}^{2}\right)$ & $27.4 \pm 2.8$ & $27.1 \pm 2.3$ & $27.1 \pm 2.4$ & NS \\
\hline ASAT $(g)$ & $24686 \pm 5617$ & $24402 \pm 7903$ & $23896 \pm 6035$ & NS \\
\hline AVAT (g) & $17530 \pm 4747$ & $15658 \pm 4754$ & $15890 \pm 4593$ & NS \\
\hline SFAT $(g)$ & $2248 \pm 760$ & $2205 \pm 849$ & $2014 \pm 488$ & NS \\
\hline SCAT $(g)$ & $7371 \pm 2620$ & $6697 \pm 2674$ & $7187 \pm 2960$ & NS \\
\hline IMAT (g) & $564 \pm 222$ & $412 \pm 260$ & $509 \pm 178$ & NS \\
\hline Systolic blood pressure $(\mathrm{mmHg})$ & $125 \pm 19$ & $133 \pm 19$ & $122 \pm 18$ & NS \\
\hline Diastolic blood pressure $(\mathrm{mmHg})$ & $80 \pm 12$ & $86 \pm 11$ & $73 \pm 20$ & NS \\
\hline $1 \mathrm{RM}$ of UE $(\mathrm{kg})$ & $17.5 \pm 6.4$ & $16.5 \pm 4.3$ & $17.3 \pm 2.8$ & NS \\
\hline 1RM of LE (kg) & $86.8 \pm 33.1$ & $86.9 \pm 24.8$ & $88.5 \pm 23.3$ & NS \\
\hline $\mathrm{FPG}(\mathrm{mg} / \mathrm{dl})$ & $125 \pm 20$ & $113 \pm 12$ & $127 \pm 19$ & NS \\
\hline $\mathrm{HbA}_{1 \mathrm{c}}(\%)$ & $7.3 \pm 0.7$ & $7.3 \pm 0.9$ & $7.7 \pm 1.0$ & NS \\
\hline C-peptide $(\mathrm{ng} / \mathrm{ml})$ & $1.7 \pm 0.6$ & $1.9 \pm 0.8$ & $1.5 \pm 0.4$ & NS \\
\hline Total cholesterol (mg/dl) & $156 \pm 38$ & $156 \pm 25$ & $157 \pm 38$ & NS \\
\hline Triglyceride $(\mathrm{mg} / \mathrm{dl})$ & $174 \pm 153$ & $185 \pm 113$ & $126 \pm 73$ & NS \\
\hline HDL cholesterol (mg/dl) & $41 \pm 15$ & $43 \pm 8$ & $46 \pm 10$ & NS \\
\hline LDL cholesterol (mg/dl) & $95 \pm 33$ & $89 \pm 26$ & $98 \pm 36$ & NS \\
\hline $\mathrm{RBP} 4(\mu \mathrm{g} / \mathrm{ml})$ & $95.0 \pm 20.5$ & $98.5 \pm 28.8$ & $87.0 \pm 25.4$ & NS \\
\hline Adiponectin $(\mu \mathrm{g} / \mathrm{ml})$ & $4.83 \pm 1.99$ & $4.98 \pm 2.52$ & $3.86 \pm 2.00$ & NS \\
\hline Leptin $(\mathrm{ng} / \mathrm{ml})$ & $11.6 \pm 5.8$ & $8.8 \pm 4.0$ & $9.86 \pm 3.06$ & NS \\
\hline$k_{\mathrm{ITT}}(\% / \mathrm{min})$ & $1.98 \pm 0.78$ & $1.76 \pm 1.00$ & $2.81 \pm 1.02$ & $P=0.011$ \\
\hline
\end{tabular}

Data are presented as mean \pm SD.

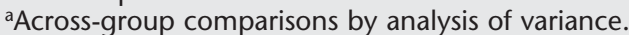

BMI, body mass index; ASAT, subcutaneous adipose tissue in abdomen; AVAT, visceral adipose tissue in abdomen; SFAT, subfascial adipose tissue at mid-thigh level; SCAT, subcutaneous adipose tissue at mid-thigh level; IMAT, intramuscular adipose tissue at mid-thigh level; 1RM, one repetitive maximum; UE, upper extremity; LE, lower extremity; FPG, fasting plasma glucose; $\mathrm{HbA}_{1 c^{\prime}}$ glycosylated haemoglobin; $\mathrm{HDL}$, highdensity lipoprotein; LDL, low-density lipoprotein; RBP4, retinol-binding protein-4; $\mathrm{k}_{\mathrm{ITT}}$, fractional disappearance rate of insulin. 


\begin{tabular}{|c|c|c|c|c|}
\hline Variable & Baseline & After training & Change & $\begin{array}{c}\text { Statistical } \\
\text { significance }\end{array}$ \\
\hline Weight (kg) & & & & $P=0.048$ \\
\hline Resistance & $66.1 \pm 4.4$ & $65.0 \pm 4.7^{b}$ & $-1.1 \pm 1.3$ & \\
\hline Aerobic & $66.3 \pm 6.0$ & $64.4 \pm 5.4^{b}$ & $-1.9 \pm 1.2$ & \\
\hline Control & $67.6 \pm 7.5$ & $67.0 \pm 7.4$ & $-0.6 \pm 1.7$ & \\
\hline $\mathrm{BMI}\left(\mathrm{kg} / \mathrm{m}^{2}\right)$ & & & & $P=0.044$ \\
\hline Resistance & $27.1 \pm 2.3$ & $26.7 \pm 2.3^{b}$ & $-0.4 \pm 0.5$ & \\
\hline Aerobic & $27.1 \pm 2.4$ & $26.3 \pm 2.1^{b}$ & $-0.8 \pm 0.5^{d}$ & \\
\hline Control & $27.4 \pm 2.8$ & $27.1 \pm 2.8$ & $-0.3 \pm 0.7$ & \\
\hline Waist circumference $(\mathrm{cm})$ & & & & NS \\
\hline Resistance & $90 \pm 5$ & $88 \pm 6^{b}$ & $-2 \pm 3$ & \\
\hline Aerobic & $89 \pm 5$ & $86 \pm 5^{b}$ & $-3 \pm 3$ & \\
\hline Control & $90 \pm 12$ & $90 \pm 6$ & $0 \pm 14$ & \\
\hline ASAT (g) & & & & $P=0.015$ \\
\hline Resistance & $24402 \pm 7903$ & $22732 \pm 7264^{b}$ & $-1670 \pm 1744^{d}$ & \\
\hline Aerobic & $23896 \pm 6035$ & $21851 \pm 5767^{b}$ & $-2045 \pm 1243^{c}$ & \\
\hline Control & $24686 \pm 5617$ & $24057 \pm 5541^{b}$ & $-629 \pm 1028$ & \\
\hline AVAT (g) & & & & NS \\
\hline Resistance & $15658 \pm 4754$ & $14678 \pm 3456$ & $-980 \pm 2353$ & \\
\hline Aerobic & $15890 \pm 4593$ & $15038 \pm 3369$ & $-852 \pm 2839$ & \\
\hline Control & $17530 \pm 4747$ & $17362 \pm 4728$ & $-168 \pm 1801$ & \\
\hline SFAT (g) & & & & NS \\
\hline Resistance & $2205 \pm 849$ & $1885 \pm 617$ & $-320 \pm 616^{d}$ & \\
\hline Aerobic & $2014 \pm 849$ & $2016 \pm 639$ & $2 \pm 687$ & \\
\hline Control & $2248 \pm 760$ & $2563 \pm 760$ & $315 \pm 868$ & \\
\hline SCAT (g) & & & & NS \\
\hline Resistance & $6697 \pm 2674$ & $7660 \pm 2760^{b}$ & $963 \pm 1157^{d}$ & \\
\hline Aerobic & $7187 \pm 2960$ & $7849 \pm 2510^{b}$ & $662 \pm 966$ & \\
\hline Control & $7371 \pm 2620$ & $7313 \pm 2479$ & $-58 \pm 1316$ & \\
\hline IMAT (g) & & & & NS \\
\hline Resistance & $412 \pm 160$ & $416 \pm 159$ & $4 \pm 199$ & \\
\hline Aerobic & $509 \pm 178$ & $478 \pm 184$ & $-31 \pm 159$ & \\
\hline Control & $564 \pm 222$ & $532 \pm 215$ & $-32 \pm 171$ & \\
\hline $1 \mathrm{RM}$ of UE $(\mathrm{kg})$ & & & & $P<0.001$ \\
\hline Resistance & $17 \pm 4$ & $19 \pm 4^{b}$ & $2 \pm 2^{\mathrm{c}, \mathrm{e}}$ & \\
\hline Aerobic & $17 \pm 3$ & $15 \pm 3^{b}$ & $-2 \pm 3^{e}$ & \\
\hline Control & $18 \pm 6$ & $16 \pm 7^{b}$ & $-2 \pm 2$ & \\
\hline $1 \mathrm{RM}$ of $\mathrm{LE}(\mathrm{kg})$ & & & & $P=0.004$ \\
\hline Resistance & $87 \pm 25$ & $97 \pm 15^{b}$ & $10 \pm 16^{\mathrm{c}, \mathrm{e}}$ & \\
\hline Aerobic & $89 \pm 23$ & $82 \pm 25$ & $-7 \pm 13^{e}$ & \\
\hline Control & $87 \pm 33$ & $75 \pm 24^{b}$ & $-12 \pm 21$ & \\
\hline FPG (mg/dl) & & & & NS \\
\hline Resistance & $113 \pm 12$ & $127 \pm 39$ & $14 \pm 39$ & \\
\hline Aerobic & $127 \pm 19$ & $120 \pm 20$ & $-7 \pm 22$ & \\
\hline Control & $125 \pm 20$ & $121 \pm 24$ & $-4 \pm 22$ & \\
\hline
\end{tabular}




\section{TABLE 2 (continued):}

Changes in all variables in 44 women with type 2 diabetes mellitus after taking part in a 12-week programme of no exercise (control, $n=16)$, resistance exercise $(n=13)$ or aerobic exercise $(n=15)$

\begin{tabular}{|c|c|c|c|c|}
\hline Variable & Baseline & After training & Change & $\begin{array}{c}\text { Statistical } \\
\text { significance }\end{array}$ \\
\hline $\mathrm{HbA}_{1 \mathrm{c}}(\%)$ & & & & NS \\
\hline Resistance & $7.3 \pm 0.9$ & $7.0 \pm 0.9$ & $-0.3 \pm 0.9$ & \\
\hline Aerobic & $7.7 \pm 1.0$ & $7.1 \pm 0.8$ & $-0.6 \pm 1.2$ & \\
\hline Control & $7.3 \pm 0.7$ & $7.2 \pm 0.9$ & $-0.1 \pm 0.6$ & \\
\hline C-peptide (ng/ml) & & & & NS \\
\hline Resistance & $1.9 \pm 0.8$ & $1.8 \pm 0.7$ & $-0.1 \pm 0.7$ & \\
\hline Aerobic & $1.5 \pm 0.4$ & $1.3 \pm 0.3^{b}$ & $-0.2 \pm 0.4$ & \\
\hline Control & $1.7 \pm 0.6$ & $1.7 \pm 0.7$ & $0.0 \pm 0.6$ & \\
\hline RBP4 $(\mu \mathrm{g} / \mathrm{ml})$ & & & & NS \\
\hline Resistance & $98.5 \pm 28.8$ & $82.1 \pm 27.1^{b}$ & $-16.4 \pm 18.1^{d, e}$ & \\
\hline Aerobic & $87.0 \pm 25.4$ & $84.7 \pm 15.3$ & $-2.3 \pm 16.9$ & \\
\hline Control & $95.0 \pm 20.5$ & $96.2 \pm 28.7$ & $1.2 \pm 23.2$ & \\
\hline Adiponectin $(\mu \mathrm{g} / \mathrm{ml})$ & & & & NS \\
\hline Resistance & $4.98 \pm 2.52$ & $7.28 \pm 3.72^{\mathrm{b}}$ & $2.30 \pm 2.09$ & \\
\hline Aerobic & $3.86 \pm 2.00$ & $6.76 \pm 1.24^{b}$ & $2.90 \pm 2.32$ & \\
\hline Control & $4.83 \pm 1.99$ & $6.82 \pm 2.39^{b}$ & $1.99 \pm 2.06$ & \\
\hline Leptin (ng/ml) & & & & $P=0.011$ \\
\hline Resistance & $8.75 \pm 3.97$ & $7.73 \pm 4.05$ & $-1.02 \pm 2.89$ & \\
\hline Aerobic & $9.86 \pm 3.06$ & $6.13 \pm 4.00^{b}$ & $-3.73 \pm 3.10^{c, e}$ & \\
\hline Control & $11.60 \pm 5.83$ & $11.50 \pm 4.92$ & $-0.10 \pm 3.52$ & \\
\hline$k_{\text {IT }}(\% / \mathrm{min})$ & & & & NS \\
\hline Resistance & $1.87 \pm 0.97$ & $2.13 \pm 0.76$ & $0.26 \pm 1.16$ & \\
\hline Aerobic & $2.81 \pm 1.02$ & $2.50 \pm 0.63$ & $-0.31 \pm 0.93$ & \\
\hline Control & $1.98 \pm 0.78$ & $2.12 \pm 0.62$ & $0.14 \pm 0.71$ & \\
\hline
\end{tabular}

Data are presented as mean \pm SD.

${ }^{a}$ Across-group comparisons by analysis of variance.

$\mathrm{b} P<0.05$ versus baseline; $c p<0.01, \mathrm{~d} p<0.05$ versus the control group; $\mathrm{e} P<0.05$ versus the other exercise group.

BMI, body mass index; ASAT, subcutaneous adipose tissue in abdomen; AVAT, visceral adipose tissue in abdomen; SFAT, subfascial adipose tissue at mid-thigh level; SCAT, subcutaneous adipose tissue at mid-thigh level; IMAT, intramuscular adipose tissue at mid-thigh level; 1RM, one repetitive maximum; UE, upper extremity; LE, lower extremity; FPG, fasting plasma glucose; $\mathrm{HbA}_{1 c^{\prime}}$ glycosylated haemoglobin; RBP4, retinolbinding protein- $4 ; k_{1 \pi}$, fractional disappearance rate of insulin.

baseline. As expected, aerobic exercise training induced a greater body weight loss in comparison with the resistance exercise group and the control group; statistically significant difference between the three groups in terms of change from baseline (resistance exercise, $-1.1 \pm 1.3 \mathrm{~kg}$; aerobic exercise, $-1.9 \pm 1.2 \mathrm{~kg}$; control, $-0.6 \pm 1.7 \mathrm{~kg}$; $P=0.048$ across-group comparison).
After the 12-week training programme, overall fat mass of the whole body was reduced in both exercise groups, but the change was significantly greater in the aerobic exercise group versus the resistance exercise group $(-5.4 \%$ versus $-1.3 \%$, respectively; $P=0.038$; data not shown). The muscular mass of the upper and lower extremities in the resistance exercise group 


\section{Resistance exercise in individuals with diabetes mellitus}

increased from baseline (upper $+5.3 \%$ and lower $+1.3 \%$, respectively), whereas that in the aerobic exercise group was unaltered (upper $-0.3 \%$ and lower $-0.1 \%$, respectively); the difference between the aerobic and resistance exercise groups was statistically significant for the upper extremities $(P=$ $0.001)$ but not for the lower extremities.

Decreases in BMI and ASAT were significantly different across the three groups $(P=0.044$ and $P=0.015$ respectively). Pair-wise multiple comparison revealed that the changes in BMI and ASAT in the aerobic exercise group were significantly greater than in the control group $(P=0.014$ and $P=0.005$, respectively), and ASAT in the resistance exercise group changed significantly more than in the control group $(P=0.044)$. The changes of SCAT, SFAT and IMAT were not statistically significantly different across the three groups, but SCAT and SFAT in the resistance exercise group changed significantly more than in the control group $(P=0.023$ and $P=0.027$, respectively, by pair-wise comparison). There was no statistically significant change in AVAT in the three groups (Table 2).

Resistance training was related to a greater increase in muscle strength compared with aerobic exercise. The resistance exercise group showed significant increases in 1RM for the upper and lower extremities (upper $+11.8 \%$ and lower $+11.5 \% ; P=0.040$ and $P=0.006$ versus baseline, respectively), whereas 1RM was reduced in the aerobic exercise group (upper $-11.8 \%$, lower $-7.9 \%$ ); the differences between the aerobic and resistance exercise groups were also statistically significant (upper, $P<0.001$; lower, $P=0.006$ ).

Leptin levels decreased significantly by $37.8 \%$ (from $9.86 \pm 3.06$ to $6.13 \pm 4.00$ $\mathrm{ng} / \mathrm{ml}, P<0.001)$ and adiponectin increased significantly by $75.1 \%$ (from $3.86 \pm 2.00$ to $6.76 \pm 1.24 \mathrm{ng} / \mathrm{ml}, P<0.001)$ in the aerobic exercise group. In the resistance exercise group, leptin levels did not change significantly after the intervention although there was a significant increase in adiponectin of $46.2 \%$ (from $4.98 \pm 2.52$ to $7.28 \pm 3.72 \mu \mathrm{g} / \mathrm{ml}, P=0.002$ ). The change in leptin, but not in adiponectin, was statistically significant across the three treatment groups $(P=0.011)$. The change in plasma RBP4 level was significantly greater in the resistance exercise group $(-16.4 \pm 18.1$ $\mu \mathrm{g} / \mathrm{ml},-16.7 \%)$ compared with the changes in the control $(1.2 \pm 23.2 \mu \mathrm{g} / \mathrm{ml},+1.3 \%$; $P=$ $0.033)$ and aerobic exercise groups $(-2.3 \pm$ $16.9 \mu \mathrm{g} / \mathrm{ml},-2.7 \% ; P=0.046)$. The change in plasma RBP4 concentration was significantly positively correlated with that in SFAT ( $r=$ $0.664, P=0.013)$ in the resistance exercise group (Fig. 1), but there was no statistically significant correlation in the aerobic exercise group $(r=-0.405)$. The changes in $k_{\mathrm{ITT}}$ and $\mathrm{HbA}_{1 \mathrm{c}}$ showed no statistically significant differences between the groups.

\section{Discussion}

There has been increasing interest in the effects of resistance training on the control of type 2 diabetes mellitus. One study revealed that resistance exercise led to significant improvements in the amount of visceral and abdominal subcutaneous adipose tissue, which has been linked to metabolic syndrome. ${ }^{16}$ In a meta-analysis, the importance of intramyocellular fat as a contributor to insulin resistance was reported. ${ }^{5}$ It is not the total amount of fat but the fat that resides within skeletal muscle cells (intramyocellular fat) and intraabdominal fat (visceral fat) that influence insulin resistance, through the systemic and local secretion of several adipokines. ${ }^{5}$

Based on these findings, the effects of 


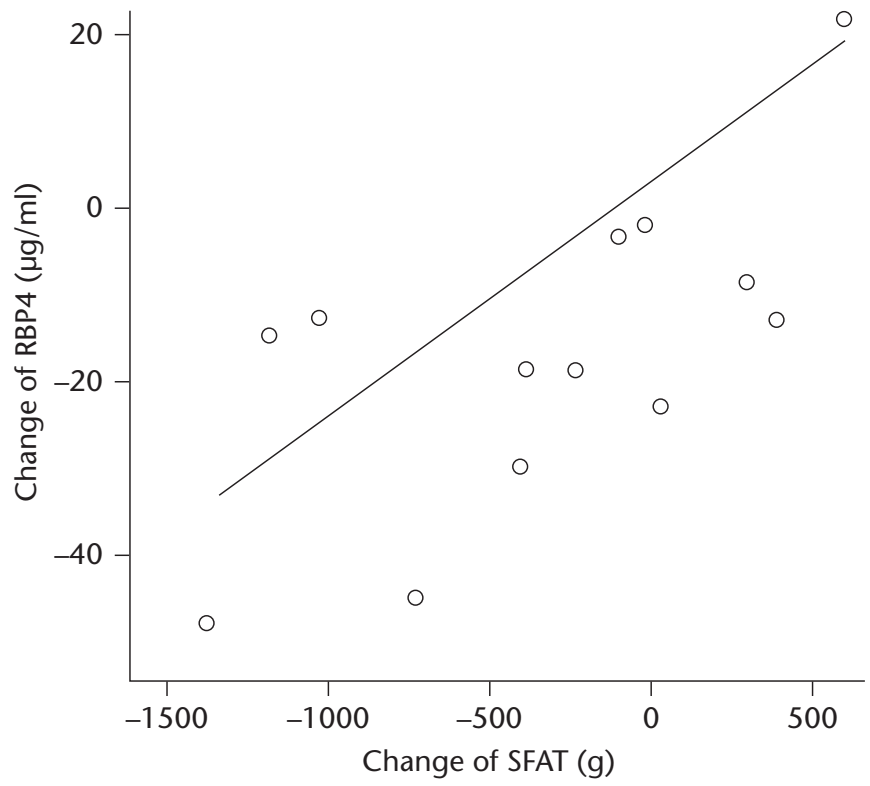

FIGURE 1: Correlation of the change in subfascial adipose tissue at mid-thigh level (SFAT) with the change in plasma retinol-binding protein-4 (RBP4) concentration during a 12-week programme of resistance exercise in 13 patients with diabetes mellitus type $2(r=0.664, P=0.013)$

different kinds of exercise on regional muscular adipose tissue were analysed in the present study. Perimuscular fat was divided into three categories - SCAT, SFAT and IMAT - and, using DXA, the effect of resistance training compared with aerobic training on each category was assessed. ASAT decreased significantly from baseline in each exercise group, and the decrease in ASAT across the three groups was also significant. No significant difference was observed across groups with respect to IMAT. Aerobic exercise was more effective in reducing adipose tissue than resistance exercise. Nonetheless, aerobic exercise was not always statistically superior to resistance exercise. For example, after 12 weeks of exercise training, maximal strength of both the lower and upper extremities increased significantly by $11.5 \%$ and $11.8 \%$, respectively, only in the resistance group. In contrast, muscle strength did not increase in the aerobic exercise group. This result is consistent with previous studies in which resistance exercise was more effective in increasing muscle power than aerobic exercise. ${ }^{17}-21$ To our knowledge, this is the first report to correlate the effects and type of exercise on categories of perimuscular adipose tissue.

One of the novel findings of this study was that the plasma RBP4 level was reduced more effectively in the resistance exercise group than in the aerobic exercise group. A few adipokines are related to the risk of developing insulin resistance, obesity, diabetes mellitus and cardiovascular disease, and there has been much interest in the effect of exercise training on adipokine levels. There have been reports that supervised exercise training reduces resistin levels ${ }^{22}$ and that resting leptin responds positively to resistance training in persons with type 2 diabetes. ${ }^{23}$ 
Boudou et al. ${ }^{24}$ reported that a supervised intensive training programme did not induce significant changes in adiponectin and leptin levels despite a tremendous decrease in abdominal fat and improvement in insulin sensitivity in sedentary middle-aged subjects with type 2 diabetes. In addition, Levinger et al. ${ }^{25}$ reported that resistance training did not reduce inflammatory markers in individuals with a large number of metabolic risk factors. Thus, the association between exercise training and adipokines remains controversial. In particular, the effect of resistance exercise on plasma RBP4 concentrations still needs to be confirmed by further studies.

An association between regional fat and RBP4 level was identified in the present study, with RBP4 concentration being positively correlated with SFAT only in the resistance exercise group but not in the aerobic exercise group. To our knowledge, this is the first report of the correlation of plasma RBP4 concentration with regional fat in relation to the type of exercise.

It has been reported that resistance training is as effective as aerobic training in improving glucose control, glucose tolerance and the insulin response in both diabetic ${ }^{13,14}$ and non-diabetic ${ }^{26-28}$ participants. In the present study, however, no superiority was observed for resistance training in terms of glycaemic control or insulin sensitivity. For example, there was no significant difference in glycaemic control among groups after the 12 week training programme, although each group showed a slight, not statistically significant decrease in $\mathrm{HbA}_{1 \mathrm{c}}$ level. After completion of the study, the raw data were re-examined and it was found that, during the randomization process, patients with better insulin sensitivity based on $k_{\text {ITT }}$ tended to be assigned to the aerobic exercise group, which may have biased the exercise effect. Furthermore, both exercise groups showed reasonable levels of glycaemic control at baseline as evidenced by the $\mathrm{HbA}_{1 \mathrm{c}}$ levels, which might have ameliorated the treatment effect.

In conclusion, the novel findings of the present study are that resistance exercise did not alter intramuscular adipose tissue but did reduce plasma RBP4 levels without improving insulin sensitivity.

\section{Conflicts of interest}

The authors had no conflict of interest to declare in relation to this article.

- Received for publication 19 November 2009 • Accepted subject to revision 10 December 2009

- Revised accepted 17 March 2010

Copyright @ 2010 Field House Publishing LLP

References

1 Pan DA, Lillioja S, Kriketos AD, et al: Skeletal muscle triglyceride levels are inversely related to insulin action. Diabetes 1997; 46: 983 - 988.

2 van Loon LJ, Koopman R, Manders R, et al: Intramyocellular lipid content in type 2 diabetes patients compared with overweight sedentary men and highly trained endurance athletes. Am J Physiol Endocrinol Metab 2004; 287: E558 - E565.

3 Storlien LH, Jenkins AB, Chisholm DJ, et al: Influence of dietary fat composition on development of insulin resistance in rats. Relationship to muscle triglyceride and omega3 fatty acids in muscle phospholipid. Diabetes
1991; 40: 280 - 289.

4 Turcotte LP, Fisher IS: Skeletal muscle insulin resistance: roles of fatty acid metabolism and exercise. Phys Ther 2008; 88: 1279 - 1296.

5 Rattarasarn C: Physiological and pathophysiological regulation of regional adipose tissue in the development of insulin resistance and type 2 diabetes. Acta Physiol (Oxf) 2006; 186: 87 - 101.

6 Oberbach A, Tonjes A, Kloting N, et al: Effect of a 4 week physical training program on plasma concentrations of inflammatory markers in patients with abnormal glucose tolerance. Eur J Endocrinol 2006; 154: 577 - 585.

7 Rasouli N, Kern PA: Adipocytokines and the 
metabolic complications of obesity. J Clin Endocrinol Metab 2008; 93(11 suppl 1): S64 S73.

8 Yang Q, Graham TE, Mody N, et al: Serum retinol binding protein 4 contributes to insulin resistance in obesity and type 2 diabetes. Nature 2005; 436: 356 - 362 .

9 Corpeleijn E, Feskens EJ, Jansen EH, et al: Lifestyle intervention and adipokine levels in subjects at high risk for type 2 diabetes: the Study on Lifestyle intervention and Impaired glucose tolerance Maastricht (SLIM). Diabetes Care 2007; 30: 3125 - 3127.

10 Kelley DE, Goodpaster BH: Effects of exercise on glucose homeostasis in Type 2 diabetes mellitus. Med Sci Sports Exerc 2001; 33(6 suppl): S495 - S501; discussion S528 - S529.

11 Meltzer S, Leiter L, Daneman D, et al: 1998 clinical practice guidelines for the management of diabetes in Canada. Canadian Diabetes Association. CMAJ 1998; 159(suppl 8): S1 - S29.

12 Ryan AS: Insulin resistance with aging: effects of diet and exercise. Sports Med 2000; 30: 327 346.

13 Dunstan DW, Puddey IB, Beilin LJ, et al: Effects of a short-term circuit weight training program on glycaemic control in NIDDM. Diabetes Res Clin Pract 1998; 40: 53 - 61.

14 Ishii T, Yamakita T, Sato T, et al: Resistance training improves insulin sensitivity in NIDDM subjects without altering maximal oxygen uptake. Diabetes Care 1998; 21: 1353 - 1355.

15 Kadoglou NP, Iliadis F, Angelopoulou N, et al: The anti-inflammatory effects of exercise training in patients with type 2 diabetes mellitus. Eur J Cardiovasc Prev Rehabil 2007; 14: $837-843$

16 Ibanez J, Izquierdo M, Arguelles I, et al: Twiceweekly progressive resistance training decreases abdominal fat and improves insulin sensitivity in older men with type 2 diabetes. Diabetes Care 2005; 28: $662-667$.

17 Hunter GR, McCarthy JP, Bamman MM: Effects of resistance training on older adults. Sports Med 2004; 34: 329 - 348.

18 Ibanez J, Gorostiaga EM, Alonso AM, et al:
Lower muscle strength gains in older men with type 2 diabetes after resistance training. J Diabetes Complications 2008; 22: 112 - 118.

19 Häkkinen K, Pakarinen A, Kraemer WJ, et al: Basal concentrations and acute responses of serum hormones and strength development during heavy resistance training in middleaged and elderly men and women. J Gerontol A Biol Sci Med Sci 2000; 55: B95 - B105.

20 Kalapotharakos V, Smilios I, Parlavatzas A, et al: The effect of moderate resistance strength training and detraining on muscle strength and power in older men. J Geriatr Phys Ther 2007; 30: 109 - 113.

21 Porter MM: Power training for older adults. Appl Physiol Nutr Metab 2006; 31: 87 - 94.

22 Kadoglou NP, Perrea D, Iliadis F, et al: Exercise reduces resistin and inflammatory cytokines in patients with type 2 diabetes. Diabetes Care 2007; 30: 719 - 721 .

23 Kanaley JA, Fenicchia LM, Miller CS, et al: Resting leptin responses to acute and chronic resistance training in type 2 diabetic men and women. Int J Obes Relat Metab Disord 2001; 25: 1474 - 1480 .

24 Boudou P, Sobngwi E, Mauvais-Jarvis F, et al: Absence of exercise-induced variations in adiponectin levels despite decreased abdominal adiposity and improved insulin sensitivity in type 2 diabetic men. Eur J Endocrinol 2003; 149: $421-424$.

25 Levinger I, Goodman C, Peake J, et al: Inflammation, hepatic enzymes and resistance training in individuals with metabolic risk factors. Diabet Med 2009; 26: 220 - 227.

26 Miller JP, Pratley RE, Goldberg AP, et al: Strength training increases insulin action in healthy 50to 65-yr-old men. J Appl Physiol 1994; 77: 1122 1127.

27 Ryan AS, Pratley RE, Elahi D, et al: Changes in plasma leptin and insulin action with resistive training in postmenopausal women. Int J Obes Relat Metab Disord 2000; 24: 27 - 32.

28 Ryan AS, Hurlbut DE, Lott ME, et al: Insulin action after resistive training in insulin resistant older men and women. I Am Geriatr Soc 2001; 49: 247 - 253.

Author's address for correspondence:

Dr Kyung-Wan Min

Department of Internal Medicine, Eulji University College of Medicine, 280-1 Hagye-Dong

Nowon-Gu, Seoul 139-711, Republic of Korea.

E-mail:minyungwa@yahoo.co.kr 